\title{
Socioeconomic Disparities in Cancer Screening: Organized versus Opportunistic
}

\author{
Young Gyu Cho \\ Department of Family Medicine, Inje University Seoul Paik Hospital, Inje University College of Medicine, Seoul, Korea
}

There are two types of cancer screening-organized and opportunistic. In organized screening, invitations to screening are issued from the government or public sector. However, opportunistic screening depends on requests from individuals or their health advisor. ${ }^{1)}$ In Korea, both organized and opportunistic cancer screening programs are widely available. In 1999, Korea launched the National Cancer Screening Program (NCSP), a nationally organized cancer screening program, which has been expanding to cover the whole population. ${ }^{2)}$ Since the introduction of NCSP, cancer screening rates in Korea have increased steadily. ${ }^{3)}$ Although NCSP is managed and implemented with an evidence-based guideline and also monitors the quality of screening services in a regular basis, some Korean people show lower levels of trust and satisfaction for NCSP compared to opportunistic screening programs. ${ }^{4)}$ Because opportunistic screening is more expensive and less efficient, public awareness on benefits of NCSP should be improved to encourage to get screened through NCSP.

It has been well known that there are socioeconomic disparities in cancer screening. ${ }^{5)}$ Lower household income, lower educational attainment, and lack of health insurance are wellestablished barriers to cancer screening. ${ }^{6)}$ Organized cancer screening is supposed to contribute to decrease of socioeconomic inequalities by removing economic barriers. It is not clear, however, whether organized screening is effective in reducing socioeconomic inequalities in cancer screening participation. Palencia et al. ${ }^{7)}$ investigated socioeconomic inequalities in breast and cervical cancer screening in European countries and the influence of the type of screening program on the extent of inequalities. They presented that socioeco- nomic inequalities in screening were found in countries with opportunistic screening, but not in countries with nationwide population-based cancer screening programs. In contrast, Decker et al. ${ }^{8)}$ showed that while colorectal cancer (CRC) screening in a city in Canada increased over time at all income levels after the introduction of an organized screening program, a disparity in screening by income still persisted. They emphasized that more targeted efforts are required to improve CRC screening for low-income individuals.

In the present issue, Kim and Kang') investigated the association between socioeconomic status (SES) and cancer screening among Koreans using the data from the Fifth Korea National Health and Nutrition Examination Survey (KNHANES V), 2010-2012. The study participants consisted of 12,303 Koreans (5,284 men and 7,019 women) aged 40 years or older. They found that the relationship between cancer screening rate and income level were different depending on the type of cancer screening. A higher income level was associated with a higher participation in opportunistic cancer screening (private cancer screening), but a lower income level was associated with a higher participation in NCSP, especially in women. Although individuals with a higher income were more likely to participate in overall cancer screening, the odds ratios for overall cancer screening of the highest income level were remarkably lower than those for opportunistic cancer screening, especially in women. This means that NCSP may make a contribution to decrease of socioeconomic inequalities in overall cancer screening through enhancing cancer screening uptake among lower socioeconomic groups.

These results are somewhat different with those of a study using data from KNHANES, 2007-2011. In that study, socio- 
economic factors had no significant association with participation in organized cancer screening with exception of increased participation in the highest income quartile. ${ }^{10)}$ Inconsistent findings between two studies should be ascertained through further study on trend in participation rate in NCSP depending on socioeconomic factors. This could be because of targeted efforts to improve participation rate in NCSP among lower socioeconomic groups in recent years.

Kim and Kang's' ${ }^{9)}$ study also shows that despites a higher participation in NCSP among lower socioeconomic groups, the socioeconomic disparity in overall cancer screening still persists. Lee et al. ${ }^{4)}$ reported six barriers to cancer screening in Korean people with low SES. They are (1) lack of trust in the NCSP and cancer screening units, (2) fear of being diagnosed with cancer or discomfort or pain form the screening procedure, (3) lack of time, (4) lack of knowledge about cancer screening or lack of awareness of the existence of the NCSP, (5) physical disability or underlying disease, and (6) logistic barriers. Tailored Interventions to address these identified barriers should be consistently implemented in Korea to improve cancer screening among those with low SES.

\section{CONFLICT OF INTEREST}

No potential conflict of interest relevant to this article was reported.

\section{REFERENCES}

1. Miles A, Cockburn J, Smith RA, Wardle J. A perspective from countries using organized screening programs. Cancer 2004;101(5 Suppl):1201-13.
2. Kim Y, Jun JK, Choi KS, Lee HY, Park EC. Overview of the national cancer screening programme and the cancer screening status in Korea. Asian Pac J Cancer Prev 2011;12:725-30.

3. Suh M, Choi KS, Lee YY, Jun JK. Trends in cancer screening rates among Korean men and women: results from the Korean National Cancer Screening Survey, 2004-2012. Cancer Res Treat 2013;45:86-94.

4. Lee YY, Jun JK, Suh M, Park BY, Kim Y, Choi KS. Barriers to cancer screening among medical aid program recipients in the Republic of Korea: a qualitative study. Asian Pac J Cancer Prev 2014;15:589-94.

5. Segnan N. Socioeconomic status and cancer screening. IARC Sci Publ 1997;(138):369-76.

6. Park MJ, Park EC, Choi KS, Jun JK, Lee HY. Sociodemographic gradients in breast and cervical cancer screening in Korea: the Korean National Cancer Screening Survey (KNCSS) 2005-2009. BMC Cancer 2011;11:257.

7. Palencia L, Espelt A, Rodriguez-Sanz M, Puigpinos R, Pons-Vigues M, Pasarin MI, et al. Socio-economic inequalities in breast and cervical cancer screening practices in Europe: influence of the type of screening program. Int J Epidemiol 2010;39:757-65.

8. Decker KM, Demers AA, Nugent Z, Biswanger N, Singh H. Longitudinal rates of colon cancer screening use in Winnipeg, Canada: the experience of a universal health-care system with an organized colon screening program. Am J Gastroenterol 2015;110:1640-6.

9. Kim JY, Kang HT. Association between socioeconomic status and cancer screening in Koreans over 40 years in age based on the 2010-2012 Korean National Health and Nutrition Examination Survey. Korean J Fam Med 2016;37:287-92.

10. Kang M, Yoo KB, Park EC, Kwon K, Kim G, Kim DR, et al. Factors associated with organized and opportunistic cancer screening: results of the Korea National Health and Nutrition Examination Survey (KNHANES) 2007-2011. Asian Pac J Cancer Prev 2014;15:3279-86. 